\title{
A comparative evaluation of glycosylated haemoglobin assays: feasibility of references and standards
}

\author{
C. M. Peterson ${ }^{1},{ }^{*}$ L. Jovanovic ${ }^{2}$, P. Raskin ${ }^{3}$ and D. E. Goldstein ${ }^{4}$ \\ ${ }^{1}$ The Rockefeller University and ${ }^{2}$ Cornell University Medical College New York, New York, ${ }^{3}$ University of Texas Health Science Center at \\ Dallas, Dallas, Texas and ${ }^{4}$ University of Missouri, Columbia, Missouri, USA
}

\begin{abstract}
Summary. Four assays; high pressure liquid chromatography, colorimetric with thiobarbituric acid, affinity columns, and microcolumn cation exchange were compared for (1) ability to discriminate between samples taken from diabetic and normal subjects; (2) correlation with each other; (3) stability over time at different temperatures; and (4) reproducibility between laboratories. The most discriminatory ( 10 samples from a diabetic and 10 samples from a normal group) was the microcolumn cation exchange method $(\mathrm{t}=5.25 ; p<0.001)$, but all were significantly different at $p<0.005$. The intra-assay coefficient of variation was $1 \%-6 \%$, except for the affinity column method which was $13 \%$ in normal subjects. High pressure liquid chromatography was used as a reference and the other assays correlated well $(\mathbf{r}=0.93-0.99)$. Storage at $-80{ }^{\circ} \mathrm{C},-20^{\circ} \mathrm{C}, 4{ }^{\circ} \mathrm{C}$, and $24{ }^{\circ} \mathrm{C}$ showed marked differences. The thiobarbituric acid method results were stable except for $24^{\circ} \mathrm{C}$. Microcolumn cation exchange was labile under all conditions. Affinity column was stable for up to
\end{abstract}

15 days, only if samples were stored as whole blood. High pressure liquid chromatography showed an increase in haemoglobin $\mathrm{A}_{1 \mathrm{a}+\mathrm{b}}$ and a decrease in the haemoglobin $\mathrm{A}_{1 c}$. Haemoglobin $A_{1 \mathrm{c}}$ was reproducible for 4 days when stored at $4{ }^{\circ} \mathrm{C}$ and up to 11 days when stored at $-80^{\circ} \mathrm{C}$. Samples exchanged between centres at $4{ }^{\circ} \mathrm{C}$ and performed within 5 days by high pressure liquid chromatography for haemoglobin $\mathrm{A}_{1}$ and haemoglobin $A_{1 c}$ correlated well $(r=0.98$ and 0.99$)$. Samples exchanged between centres after storage (up to 40 days $-80^{\circ} \mathrm{C}$ ) correlated $(r=0.99)$ by the thiobarbituric acid method. Thus, standards can be prepared for the thiobarbituric acid method and this method with high pressure liquid chromatography could be used to establish references for clinical assays.

Key words: Glycosylated haemoglobin, standards, references, microcolumn, high pressure liquid chromatography, thiobarbituric acid, affinity column.
The measurement of glycosylated haemoglobin has provided clinicians with a means whereby mean blood glucose values over the previous 4-8 weeks can be quantitated [1]. Using these assays, it has been possible to redefine diabetic control and readdress questions related to the role of hyperglycaemia in a number of diabetic sequelae. The utility of these assays has been limited because there are no standards with which results can be compared. A number of assays are now available. Some separate haemoglobins by physical means, others quantitate glycosylation chemically. The present study was undertaken to evaluate four assays (two physical separation techniques and two chemical assays) in terms of (1) discrimination of a diabetic from a non-diabetic group of patients, (2) intra- and interassay comparability, (3) consistency over time and (4) reproducibility between laboratories where possible.

\footnotetext{
* Present address: Sansum Medical Research Foundation, Santa Barbara, California, USA
}

\section{Materials and methods}

Blood was obtained in EDTA from diabetic patients and normal subjects and informed witnessed consent was received from all subjects. Unless stated otherwise, blood was incubated in $0.9 \%$ saline for at least $18 \mathrm{~h}$ at $4{ }^{\circ} \mathrm{C}$ after three washes in $0.9 \%$ saline to eliminate the labile adduct before analysis [2] and stored following lysis as haemolysates in 1:1 distilled $\mathrm{H}_{2} \mathrm{O}$. All samples were prepared in our laboratory. Storage was performed in separate aliquots which were retrieved at various time intervals. Room temperature storage was performed in an air-conditioned room at $20^{\circ}-26^{\circ} \mathrm{C}$. Other temperatures utilized refrigerators or freezers with temperature control as indicated. All tests by each method were performed utilizing the same aliquot at the designated times and storage temperatures.

High pressure liquid chromatography analysis (HPLC) for physical separation of haemoglobins $\mathrm{A}_{1 \mathrm{a}+\mathrm{b}}\left(\mathrm{Hb}_{1 \mathrm{a}+\mathrm{b}}\right)$ and haemoglobin $\mathrm{A}_{1 \mathrm{c}}\left(\mathrm{HbA}_{1 \mathrm{c}}\right)$ utilized a commercially available cation exchange column with buffers and programme supplied by the manufacturers (Daichi, Kyoto, Japan). Microcolumns (for determination of $\mathrm{Hb}_{1 \mathrm{am}}$ or $\mathrm{HbA}_{1}$ ) were obtained as prepackaged columns and utilized according to the manufacturers instructions (Helena Laboratories, Beaumont, Texas). Two chemical approaches were evaluated. Affinity chromatography (to determine Cis-diol adducts) was performed using prepackaged boronate resins according to the manufacturers instructions (Isolab, Akron, Ohio), while the thiobarbituric acid colorimetric (colour) assay used was that of Parker et al [3]. 


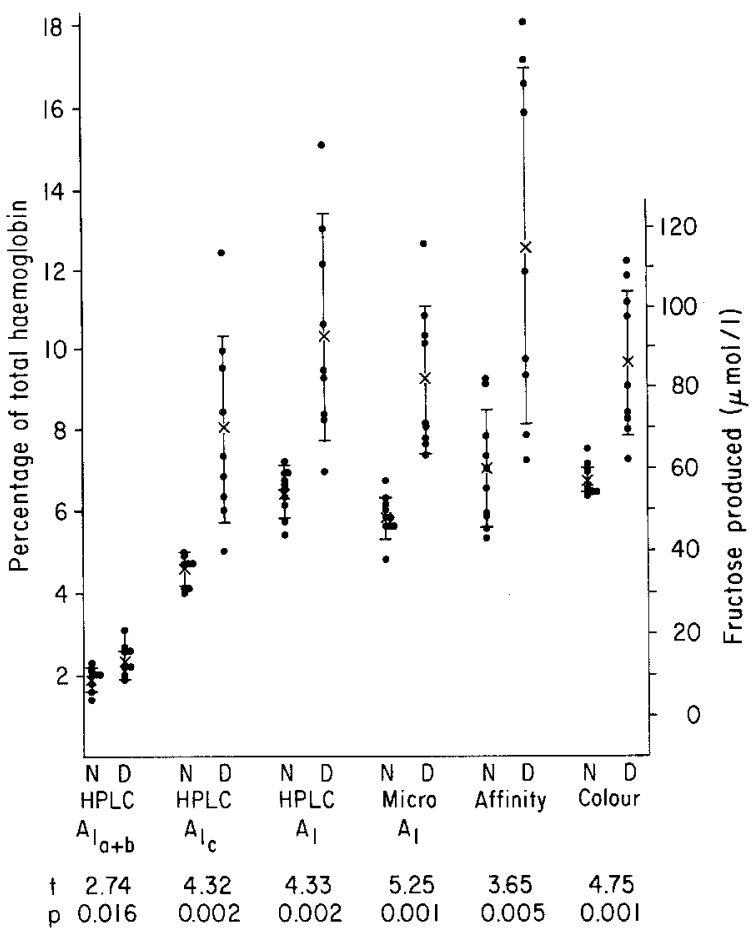

Fig. 1. Comparison of values in a normal group $(\mathrm{N})$ versus a diabetic group (D) according to each assay. The $t$ statistic and $p$ value comparing each set of data points are listed below. Mean \pm SD is indicated by an $\mathrm{x}$ and upper and lower bracket lines respectively. The left ordinate indicates percentage total haemoglobin, while the right indicates fructose produced and refers to the colorimetric assay only

Table 1. Intra-assay variations and comparison of each method versus $\mathrm{HbA}_{1 \mathrm{c}}$ by high pressure liquid chromatography

\begin{tabular}{|c|c|c|c|c|}
\hline \multirow[t]{2}{*}{ Method } & \multirow[t]{2}{*}{ r value } & \multirow[t]{2}{*}{$y$ intercept } & \multicolumn{2}{|c|}{ Intra-assay variation $(\%)$} \\
\hline & & & $\begin{array}{l}\text { Non-diabetic } \\
\text { samples }\end{array}$ & $\begin{array}{l}\text { Diabetic } \\
\text { samples }\end{array}$ \\
\hline HPLC $A_{1 c}$ & 1 & 0 & 3.1 & 6.2 \\
\hline $\mathrm{A}_{1 \mathrm{a}+\mathrm{b}}$ & 0.75 & -2.8 & 1.8 & 6.2 \\
\hline $\mathrm{A}_{1}$ & 0.99 & -1.0 & 1.1 & 6.0 \\
\hline Microcolumn $\mathrm{A}_{1}$ & 0.95 & -1.5 & 4.9 & 3.2 \\
\hline Affinity Cis-diol & 0.93 & 1.2 & 12.7 & 3.1 \\
\hline $\begin{array}{l}\text { Colorimetric } \\
\text { thiobarbituric } \\
\text { acid }\end{array}$ & 0.97 & -2.0 & 4.9 & 3.6 \\
\hline
\end{tabular}

Statistical analysis utilized the Rockefeller University PDPI with a statistical package from the University of California, Berkeley for computation of the t-statistic and linear regression analysis.

\section{Results}

Figure 1 documents the various values obtained by each assay in a group of 10 normal volunteers and 10 diabetic patients during a routine clinic visit in a single afternoon and performed in the laboratory at Rockefeller University. The most discriminatory assay in distinguishing the two groups was the cation exchange $\mathrm{HbA}_{1}$ assay by microcolumns $(t=5.25, p<0.001)$. Each assay discriminated between the two groups with a $p$ value $<0.01$ except HPLC analysis of the $\mathrm{HbA}_{1 \mathrm{a}+\mathrm{b}}$ fraction $(t=2.74, p=0.16)$.
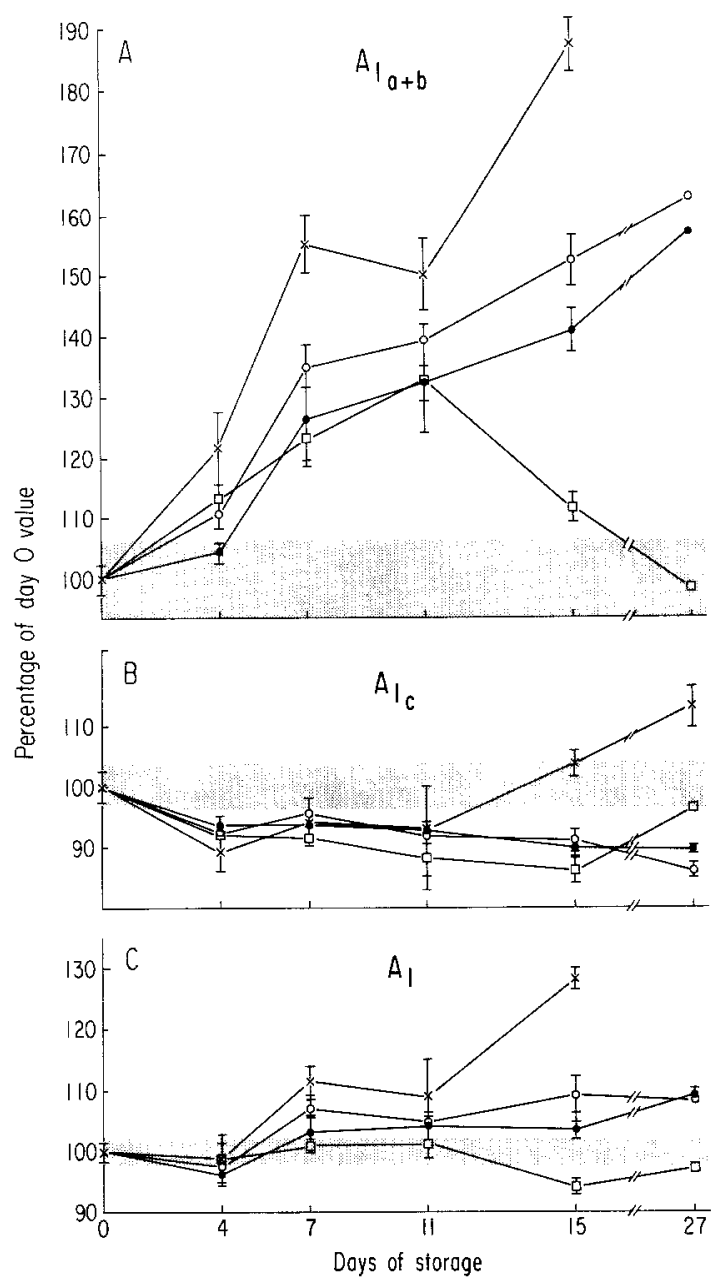

Fig. 2. Stability of HPLC assay values from a normal sample stored at various temperatures over time. Panel $\mathrm{A}: \mathrm{HbA}_{1 \mathrm{a}+\mathrm{b}}$ fraction, panel $\mathrm{B}$ : $\mathrm{HbA}_{1 \mathrm{c}}$ fraction, and panel $\mathrm{C}: \mathrm{HbA}_{1}\left(\mathrm{HbA}_{1 \mathrm{a}-\mathrm{c}}\right)$. The shaded area indicates the intra-assay coefficient of variation $\pm 2 \mathrm{SD}$. The values from day 0 are expressed as $100 \%$ with subsequent values expressed as a percentage of the day 0 value. Symbols are as follows: $(x)=$ room temperature, $(\bullet)=4{ }^{\circ} \mathrm{C},(0)=-20^{\circ} \mathrm{C}$ and $(\square)=-80^{\circ} \mathrm{C}$

The values from one diabetic patient who was found to have sickle cell trait were excluded (Fig. 1). This patient had low values utilizing physical separation techniques but higher values utilizing chemical methods. The latter methods are thus more appropriate for evaluating persons with haemoglobinopathies. An abnormal pattern, however, could be appreciated on the HPLC chromatogram, but not from the other assay systems.

Intra-assay variation for each method was evaluated by running one normal and one diabetic sample 10 times. The coefficient of variation (standard deviation as a percentage of the mean of 10 measurements) is summarized in Table 1 . As can be seen, most assays had reasonable intra-assay precision $(1 \%-6 \%)$ except for affinity chromatography which had a coefficient of variation of $12.7 \%$ in the normal group. It is important that intra-assay variation may vary between normal and diabetic samples (Table 1 ).

Interassay variation was determined by analysis of blood from the same normal individual drawn on 10 

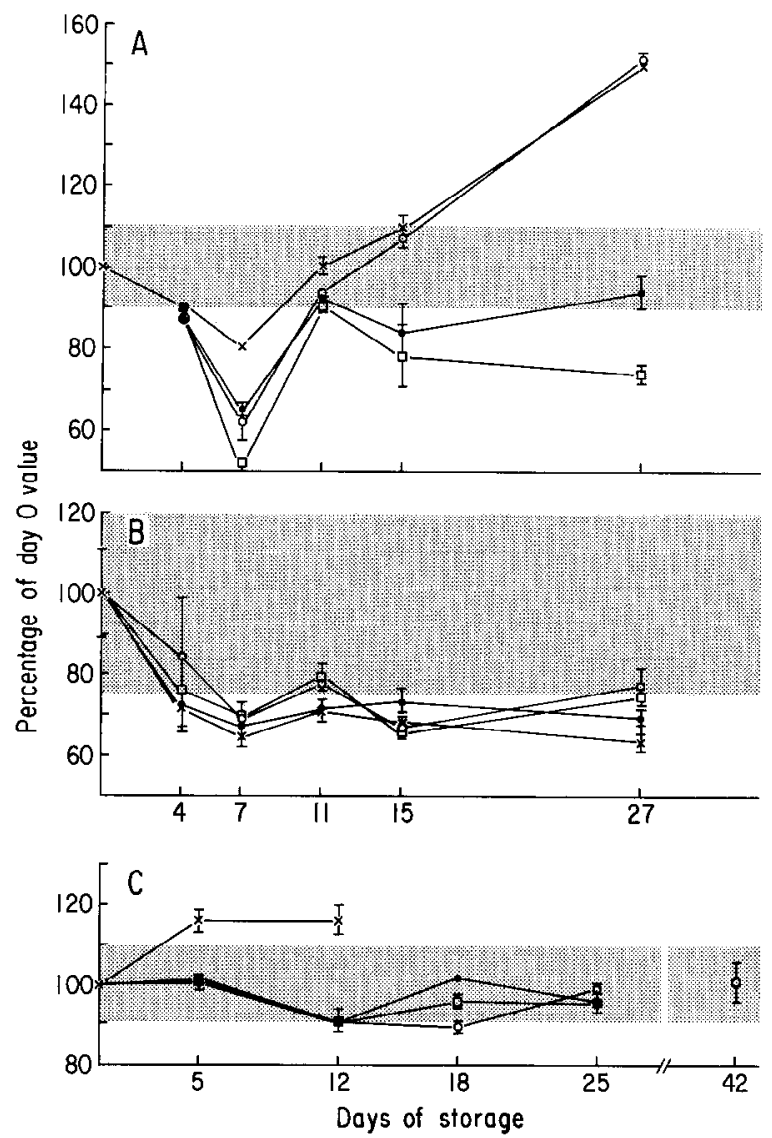

Fig. 3. Stability of microcolumn (panel A), affinity column (panel B), and colorimetric (panel C) assay values from the same sample as in Figure 2 stored at various temperatures over time. The symbols are the same as Figure 2. The shaded areas indicate the intra-assay coefficient of variation $\pm 2 \mathrm{SD}$. The values from day 0 are expressed as $100 \%$ with subsequent values expressed as a percentage of the day 0 values

successive assay days. Interassay variations for the different procedures were as follows: colorimetric $8.6 \%$, affinity chromatography $6.8 \%$, microcolumns $4.4 \%$, $\mathrm{HbA}_{1 \mathrm{a}+\mathrm{b}}$ by HPLC $14.1 \%, \mathrm{HbA}_{1 \mathrm{c}}$ by HPLC $1.9 \%$, and $\mathrm{HbA}_{1}$ by HPLC $3.7 \%$.

For comparison of the various analytical procedures, $\mathrm{HbA}_{1 \mathrm{c}}$ by HPLC was arbitrarily designated as the reference. Table 1 documents that each assay correlated well with $\mathrm{HbA}_{1 \mathrm{c}}$ analysis by HPLC with $r>0.90$ (except for $\left.\mathrm{HbA}_{1 \mathrm{a}+\mathrm{b}}=0.75\right)$ and $\mathrm{y}$ intercepts close to $0(-2.8$ to 1.2).

Samples were stored under various conditions to determine the stability of each assay over time. Figure 2 shows the effect of storage on a normal sample assayed in triplicate by HPLC. The diabetic sample showed deviation from the intra-assay coefficient of variation at the same time points but, as noted above, the intra-assay coefficient of variation for diabetic samples was greater than for non-diabetic samples. The $\mathrm{HbA}_{1 \mathrm{a}+\mathrm{b}}$ fraction showed the greatest lability with a consistent increase in amount assayed. The $\mathrm{HbA}_{1 \mathrm{c}}$ fraction showed a slight decrease except for samples stored at $24^{\circ} \mathrm{C}$ which had
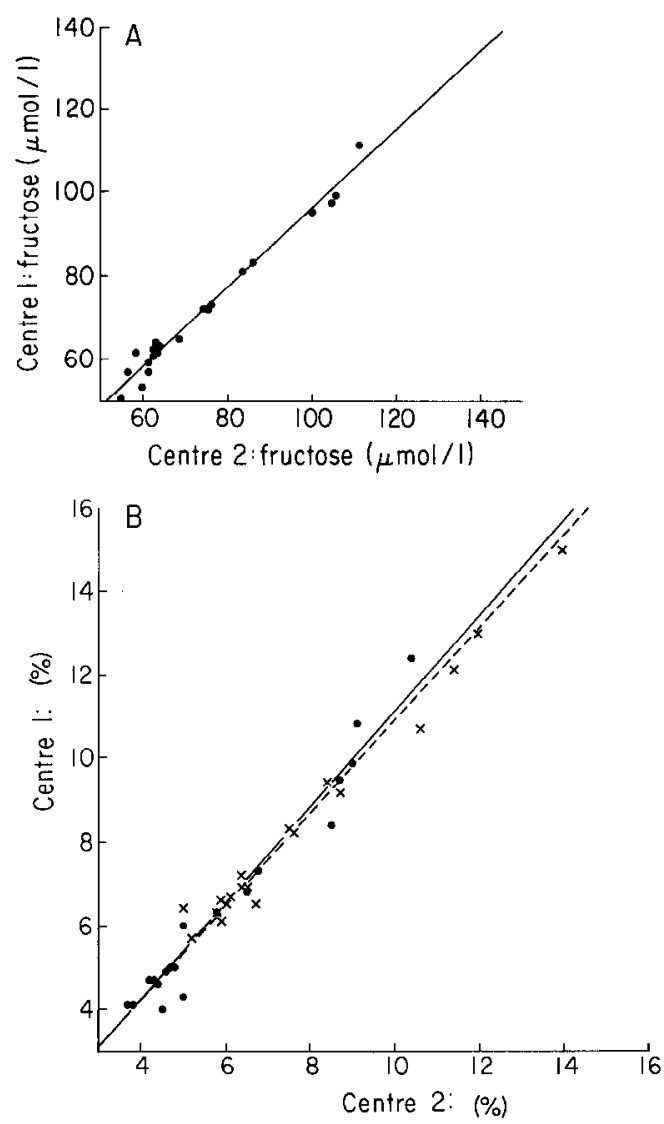

Fig.4. Panel A shows the correlation between values obtained on samples performed at two centres by colorimetric analysis (see text for conditions of assays), while panel $B$ shows the results from two centres utilizing high performance liquid chromatography. The colorimetric assay showed excellent correlation $(y=0.95 \mathrm{x}+1.2, r=0.99)$. The HPLC method resulted in highly reproducible results as well for both $\mathrm{HbA}_{1 \mathrm{c}}(\mathrm{y}=1.15 \mathrm{x}-0.44, \quad r=0.98$, solid line $)$ and $\mathrm{HbA}_{1}$ $\left(\mathrm{y}=1.10 \mathrm{x}-0.16, r=0.99\right.$, dotted line). $\mathrm{x}=\mathrm{A}_{1 \mathrm{c}} ; \bullet=\mathrm{A}_{1}$

elevated values after 15 days. $\mathrm{HbA}_{1}$ by $\mathrm{HPLC}$ was reliable after 4 days only in samples stored at $-80^{\circ} \mathrm{C}$.

Figure 3 documents changes over time under conditions of storage for analyses performed by microcolumn, affinity column, and colorimetric thiobarbiuric acid procedures. The colorimetric analyses did not deviate from two standard deviations of the intra-assay coefficient of variation over the time course evaluated except in the case of samples stored at room temperature. Results by affinity chromatography deviated beyond 2 standard deviations of the intra-assay variation after 4 days. An additional experiment with samples stored as whole blood at $4{ }^{\circ} \mathrm{C}$ or $24^{\circ} \mathrm{C}$ (not shown) documented that values performed by affinity chromatography were stable up to 14 days. Microcolumns showed considerable lability under all storage conditions. To test the feasibility of intercentre standardization of methodologies, 10 normal and 10 diabetic samples were shipped to two different centres utilizing the same procedures for colorimetric analysis (Fig. 4 upper panel) and HPLC (Fig. 4 lower panel). All samples were assayed as unknowns. The colorimetric assay was highly 
consistent between the two centres for periods of up to 3 months on the same samples $(r=0.99)$ stored at $-80^{\circ} \mathrm{C}$ and shipped on dry ice. HPLC samples were stored at $4{ }^{\circ} \mathrm{C}$, shipped on ice and analyzed within 5 days. Both shipments were by parcel post.

Analysis of $\mathrm{HbA}_{1}$ by HPLC was slightly more consistent between centres $(r=0.99$, slope $=1.10$, y intercept $=0.16)$ than analysis of $\mathrm{HbA}_{1 \mathrm{c}}(r=0.98$, slope $=1.15$, y intercept $=0.44$ ) but both showed excellent consistency. Both centres identified the sickle cell trait sample with an abnormal chromatogram.

\section{Discussion and conclusions}

All assays were able to discriminate adequately between a diabetic and a non-diabetic group. All gave reproducible values, although affinity chromatography for Cisdiol adducts performed on normal subjects showed a coefficient of variation two to three times that of the other assay systems employed. All assays correlated well with $\mathrm{HbA}_{1 \mathrm{c}}$ performed by HPLC $(r>0.90)$ which was arbitrarily designated as the reference. Marked differences were documented regarding the effect of storage and temperature on the different assay procedures. Microcolumns were not suitable for analysis of samples stored under any conditions over 4 days. Others have found that certain microcolumn procedures performed on whole blood stored at $4{ }^{\circ} \mathrm{C}$ in EDTA provide reproducible results for 7-10 days [4-6]. The colorimetric assay was the most stable over time under all storage conditions except room temperature. HPLC analysis showed a slight but significant change over time with $\mathrm{HbA}_{1 \mathrm{a}+\mathrm{b}}$ values drifting upward and $\mathrm{HbA}_{1 \mathrm{c}}$ values drifting slightly downward. $\mathrm{HbA}_{1}$ values by HPLC were therefore most stable over time as was found by better inter-centre agreement on samples performed after 5 days stored at $4{ }^{\circ} \mathrm{C}$. Storage at $-80^{\circ} \mathrm{C}$ gave the most reproducible results over time by HPLC.

The affinity columns appeared to give reproducible results over time if the samples were stored as whole blood at either room temperature or $4{ }^{\circ} \mathrm{C}$. Washing and lysing the cells prior to storage appears to lead to greater variation in values assayed by affinity chromatography. Further developmental work in terms of intra-assay variation and storage of samples is necessary before the clinical utility of affinity chromatography can be fully appreciated.

Performance of the same samples run at different centres provided highly consistent results. Colorimetric analysis was slightly more consistent and demonstrated superior storage over time as has been documented by a number of centres $[4,7]$. HPLC analysis was performed at each site within one week of phlebotomy. $\mathrm{HbA}_{1}$ values were slightly more consistent between centres than $\mathrm{HbA}_{1 \mathrm{c}}$ values probably because of the greater storage consistency of $\mathrm{HbA}_{1}$ due to the increase in $\mathrm{HbA}_{1 \mathrm{a}+\mathrm{b}}$ compensating for the decrease in $\mathrm{HbA}_{1 \mathrm{c}}$. Samples for HPLC analysis were not diluted and therefore the data reported probably reflect minimum storage potential for this system.

The present study demonstrates the feasibility and provides impetus for the establishment of references and standards for glycosylated haemoglobin methodologies. Such an approach has been questioned recently [8]. In view of the marked influence of various storage conditions on assay results documented above, the disappointing results of Boucher et al. may have been due more to differences arising during transit rather than in the procedures themselves. The colorimetric assay provides a method which could be utilized for the establishment of stored standards. In addition, this method would appear to be optimal at this point for use in collaborative clinical trials. Nevertheless, each method correlated well with others. Therefore, references for each of the above methods could be established against a standard assuming that samples are distributed within the time constraints of each assay as noted above. In view of the increasingly widespread clinical and investigative use of glycosylated haemoglobin assays, international agreement regarding these issues is overdue.

Acknowledgments. L. Walker, Wm. White, A. Baxevanis, J. D. England, H.M. Wiedmeyer, T.Curtis and K. Sullivan provided the technical expertise which made this work possible. We thank F. Anzel and D. Kerr for their concern in the preparation of the manuscript. Supported in part by NIH grants RR000102, RR00047, AM30627, NICHD-EBRP, ROI AA04851, NIH 1-MO1-RR0063, the American Heart Association, Helena Labs and the Diabetes Self Care Program, New York City.

\section{References}

1. Peterson CM (ed) (1982) Symposium on non-enzymatic glycosylation and browning reactions. Diabetes 31 (Suppl 3): 11-82

2. Goldstein DE, Peth SB, England JD, Hess RL, DaCosta J (1980) Effects of acute changes in blood glucose on $\mathrm{HbA}_{1 c}$. Diabetes 29: 623-629

3. Parker KM, England JD, DaCosta J, Hess RL, Goldstein DE (1981) Improved colorimetric assay for glycosylated hemoglobin. Clin Chem 27: 669-672

4. Pecoraro RE, Graf RJ, Halter JB, Beiter H, Porte D Jr. (1979) Comparison of a colorimetric assay for glycosylated hemoglobin with ion-exchange chromatography. Diabetes 28:1120-1125

5. Schauder P, Hintz W (1981) Bestimmung glykosylierter Haemoglobine mit dem "Fast Hemoglobin Test System." Dtsch Med Wochenschr 106: 262-266

6. Baron MD, Shenouda FS, Sonksen PH (1980) Micro-column method for $\mathrm{HbA}_{1}$ determination. Lancet 1: 1140

7. Fluckiger R, Winterhalter $\mathrm{KH}$ (1976) In vitro synthesis of hemoglobin $\mathrm{A}_{1 \mathrm{c}}$. FEBS Lett $71: 356-360$

8. Boucher BJ, Burrin JM, Gould BJ, John PN, Lewis G, Owens C, Paisey R, Pennoch CA, Poon PYW, Ross JS, Welch SG, White JM (1983) A collaborative study of the measurement of glycosylated haemoglobin by several methods in seven laboratories in the United Kingdom. Diabetologia 24: 265-271

Received: 14 June 1983

and in revised form: 9 September 1983

Dr. C.M. Peterson

The Rockefeller University

1230 York Avenue

New York, New York 10021, USA 